\title{
Addiction Science: A Rationale and Tools for a Public Health Response to Drug Abuse
}

\author{
Richard A. Rawson, $\mathrm{PhD},{ }^{1}$ \\ Traci Rieckmann, $\mathrm{PhD},{ }^{1,2}$ \\ Steven W. Gust, $\mathrm{PhD}^{3}$
}

\begin{abstract}
New scientific knowledge and effective, evidence-based interventions have provided health leaders and policymakers a remarkable paradigm to guide the development of addiction treatment services around the world. The definition of addiction as a brain disease, validated screening and assessment tools, medication-assisted treatment, and effective behavioral treatments have served as vehicles for both the United States and other countries to guide the transformation of their substance abuse treatment systems. Seeking to expand international research and infrastructure, the National Institute on Drug Abuse (NIDA)'s International Program has engaged international investigators and institutions in addiction research to promote dissemination of addiction science globally. This paper presents three mixed-methods case studies to exemplify the use of advancements in evidence-based practice in addiction treatment as guides and tools for the creation or further development of treatment systems in three countries, Vietnam, Lebanon, and Abu Dhabi. Results indicate that a framework of evidence-based medicine and empirical science creates a necessary platform from which objective conversations about addictions may begin. Other facilitative factors that help create treatment programs internationally include: a receptive and supportive government, support from international donors and technical experts, networking and interest from other international organizations, and often a synergistic and concerted effort by multiple entities and partners. Despite substantial differences in the circumstances that generated these initiatives and the varying scope of the services, common themes across these efforts have been the implementation of science-based approaches to systems transformation and support for a public health approach to addressing drug abuse and addiction.
\end{abstract}

\footnotetext{
${ }^{1}$ Integrated Substance Abuse Programs, Semel Institute for Neuroscience and Human Behavior, David Geffen School of Medicine at UCLA, Los Angeles, CA, USA.

${ }^{2}$ Oregon Health \& Science University, School of Medicine, Department of Public Health, OR, USA.

${ }^{3}$ National Institute on Drug Abuse, US National Institutes of Health, Bethesda, MD, USA.
}

Corresponding Author Contact Information: Richard A. Rawson at rrawson@mednet. ucla.edu; UCLA Integrated Substance Abuse Programs, 11075 Santa Monica Blvd., Ste. 200, Los Angeles, CA 90025-7535, USA. 
Key Words: Addiction science, international addiction treatment systems

Recommended Citation: Rawson RA, Rieckmann T, Gust SW. Addiction science: a rationale and tools for a public health response to drug abuse. Public Health Reviews. 2014;35: epub ahead of print.

\section{INTRODUCTION}

The development of treatment services for individuals with substance use disorders has been driven by a diverse set of forces and considerations. In many societies, drug abuse and addiction treatment began as part of the criminal justice system, social service system, community-based self-help efforts, or some combination of all three. Initial efforts to develop "treatments" were based on a limited understanding of addiction neurobiology, a lack of science-based medicine, and an overall lack of consensus about what was being treated. For example, in the late 1950s, when therapeutic communities were developed, the model was based on a combination of peer support, untested interpersonal methods, and a variety of personal opinions of members and leaders. There was not a shred of neurobiology or medical knowledge about addiction guiding the approach. ${ }^{1}$ In addition, the initial efforts to develop "treatments" for addicted individuals were frequently made by people who were unclear about what they were treating. Is drug addiction a moral problem or a medical problem? Are addicted individuals bad people, weak in character, or sick and in need of medical/psychiatric treatment?

Factors that have spurred societies to develop drug treatment services include concerns about drug-related crime; injection-related infectious diseases (e.g., HIV, hepatitis C); the loss of work productivity; healthcare costs for drug-related medical consequences; and the disruption to family members and communities. ${ }^{2-4}$ The first response to drug use has often been a public safety response to address drug-related crime..$^{5-7}$ For example in many parts of the world (e.g., Vietnam, China, and much of Southeast Asia), prior to the relatively recent initiation of methadone treatment for heroin addiction, extensive networks of compulsory centers were developed where drug users were committed for periods of years, without any meaningful treatment. Incarceration of addicted individuals in prisons, compulsory centers, and mental hospitals has been widely employed in many parts of the world.

Initial treatment alternatives have been a patchwork of storefront counseling centers, therapeutic communities, sober living houses, self-help programs, and treatments for overdose and withdrawal. ${ }^{1}$ Within the last century, the science of addiction and evidence-based medicine has progressed, driving changes in policies, service delivery, training, treatment options, and 
care coordination across public health and social service systems. One example of science driving shifts in treatment in the United States occurred when the results of the first small clinical trial with methadone for heroin addiction were reported by Dole and Nyswander. ${ }^{8}$ The results of this study, and subsequent research over the next 40-plus years, provided the needed data to support dissemination of methadone treatment throughout the US and, subsequently, throughout the world. Since the publication of the landmark Dole and Nyswander study, the National Institutes of Health (NIH) has funded a considerable amount of research on the causes and consequences of drug addiction, as well as strategies for treating it. However, until the late $20^{\text {th }}$ century, a majority of treatment services for drug dependence in the US continued to be based on a "social model" and self-help program philosophies with little scientific foundation. This disparity between the extensive empirical knowledge being developed by the NIH and the paraprofessional services being delivered as treatment came to be known as the "researchpractice gap.", 10

The Institute of Medicine report "Bridging the Gap Between Practice and Research: Forging Partnerships with Community-Based Drug and Alcohol Treatment" ${ }^{11}$ played a major role in accelerating the transfer of the findings from NIH science to application in treatment settings. Among the initiatives that emerged from this report were the U.S. National Institute on Drug Abuse (NIDA) Clinical Trials Network (CTN), ${ }^{12}$ the U.S. Substance Abuse and Mental Health Services Administration's (SAMHSA) Addiction Technology Transfer Center (ATTC) network, ${ }^{13}$ and their combined collaborations as seen in the NIDA-SAMHSA Blending Initiative Products ${ }^{14}$ and monographs (ATTC Treatment Improvement Protocols: TIPs) designed to translate NIH-generated scientific knowledge into workforce training materials and treatment protocols. ${ }^{15}$

Although the activities and products that were developed to bridge the research-practice gap were undertaken primarily to create increased synergy and interaction between US scientists and practitioners, a byproduct of this effort has been that addiction science also became more accessible to researchers, clinicians, and policymakers outside the US. To further stimulate research abroad, help build research capacity and infrastructure, and increase the global awareness of addiction science, NIDA formalized and expanded its International Program in the early 1990s. Through its initiatives, the NIDA International Program has been a major facilitator of new efforts to engage international investigators and institutions in addiction research (often in collaboration with researchers in the US) and a major promoter and vehicle for the dissemination of addiction science globally. NIDA has 
provided research funding support for hundreds of international projects and sponsored or co-sponsored dozens of international conferences and training events over the past 20 years to build the knowledge base on addiction science and to increase awareness of addiction science and its application.

A significant aspect of NIDA's international efforts is the various postdoctoral and other training exchanges that have been developed to help build a cadre of international researchers as well as practitioners and policymakers with a strong foundation in addiction science. From 1990 through 2013, NIDA has sponsored 415 international fellows from 103 countries for training fellowships via the Hubert H. Humphrey Fellowship Program, the NIDA INVEST Drug Abuse Research Fellowship, and several other programs. ${ }^{16}$ Further, NIDA has established seven binational agreements with other countries to promote co-funding of research projects, binational exchanges, and other collaborative activities to take advantage of opportunities outside the US and to foster the adoption of evidence-based programs and policies abroad. Significantly, NIDA has supported an international satellite meeting to the annual College on Problems of Drug Dependence (CPDD) conference, the largest research conference on drug abuse and addiction in the world. This CPDD International satellite meeting has shown tremendous growth from a meeting of 20-25 participants at the first meetings in the early 1990s to 300 enrollees from over 40 countries at the 2013 meeting.

Another factor that contributed to the dissemination of addiction science was the establishment of the International Society of Addiction Medicine (ISAM), which developed from a small forum of medical doctors interested in addiction to a large annual meeting of 400-500 participants. The annual ISAM meeting agendas reflect the latest scientific developments in the field, with an emphasis on clinical applications of addiction medicine. Numerous national and regional professional groups (e.g., the Australasian Professional Society on Alcohol \& other Drugs (APSAD) and the European Opiate Addiction Treatment Association (Europad)) also are important forums promoting the application of addiction science. The World Health Organization (WHO) and United Nations Office on Drugs and Crime (UNODC) have also taken an active role in the dissemination of addiction science. The UN Treatnet Program, initiated in 2007 as a UNODC initiative, has been incorporated into a joint WHO-UNODC effort to provide training and technical assistance internationally to regions developing treatment and harm reduction services. The Treatnet curriculum has an emphasis on science-based knowledge and evidence-based practices at its core ${ }^{17}$ As of 2013, more than 1,200 individuals have been trained as trainers and 9,000 clinicians have received training via Treatnet. ${ }^{18,19}$ 


\section{CONCEPTS AND TOOLS THAT HAVE PROMOTED THE DIS- SEMINATION OF ADDICTION SCIENCE}

\section{Science-based Knowledge: Addiction as a Brain Disease}

A benchmark in the effective communication that drug abuse and addiction are within the realm of healthcare was the 1998 editorial in the journal Science titled "Addiction is a Brain Disease: And it Matters." ${ }^{20}$ In this article, the then director of NIDA, Alan Leshner, made the case for how advances in brain imaging science provided the necessary scientific foundation for articulating addiction as a neurobiological disorder. This message, presented by many researchers using MRI and PET images of brain structures and brain chemistry levels altered by drug use/addiction, resonated positively across a broad range of audiences. Using this conceptualization of addiction, it was possible to communicate that the cognitive, decision-making, memory, and impulse-control capabilities of addicted individuals were impaired and that their brains were "injured."21 This explanation for addiction, with the assistance of brain imaging results, was a major communication "bridge" that was central to the acceptance of addiction as a health problem requiring treatment based on medical science.

\section{Pharmacotherapies}

Addiction medications, including methadone, buprenorphine, and naltrexone, have played a major role in promoting acceptance of addiction as a treatable medical condition. It is highly likely that of all the scientific developments that have furthered the perspective that addiction is a health condition, effective addiction pharmacotherapies have played the most important role. Specific examples of medications and their global public health impact are described below.

\section{Methadone}

Treatment of opiate dependence with methadone is a practice that was widely disseminated in the US in the 1970s. ${ }^{22}$ Over the next two decades, methadone became a well accepted treatment in many parts of Western Europe, Canada, and Australia. However, despite voluminous evidence in support of its safety and effectiveness, methadone has generated great controversy and debate. In societies where drug addiction is viewed primarily as a legal $/ \mathrm{moral}$ problem and abstinence from all drugs (including medications) is the only accepted treatment goal, methadone treatment is problematic.

During the past 20 years, research has documented that methadone treatment reduces injection opioid use and, consequently, the spread of HIV. 
These research findings have made these ideological debates about the nature of addiction a moot point in many societies. ${ }^{23-25}$ Major programs of methadone implementation are under development in Asia and Southeast Asia, including China and Vietnam, in Central Asia, including Iran, and in Eastern Europe. As these countries have implemented methadone treatment, ministries of health, as opposed to criminal justice systems, have become increasingly responsible for addressing drug abuse and addiction in these societies. The debate about the "morally correct" treatment for opioid addiction has shifted to a question of what is the most effective approach to reducing the morbidity and mortality from drug use.

\section{Buprenorphine}

The U.S. Food and Drug Administration (FDA) approved buprenorphine and Suboxone ${ }^{\circledR}$ (buprenorphine plus naloxone) for the treatment of opiate dependence in the early 2000s ${ }^{26}$ In the US and Europe, utilization of buprenorphine has expanded dramatically in the last decade..$^{27,28} \mathrm{~A}$ decade after buprenophine's FDA approval, it is estimated that over 500,000 individuals are currently in treatment with the medication (primarily Suboxone; R. Johnson, personal communication, 3 September 2013). In many countries where methadone is currently used, it is used in the context of licensed clinics under many layers of regulations and restrictions. However, buprenorphine is commonly used within the broader healthcare system, outside of clinics with restrictive and costly regulations. ${ }^{29,30}$ As a result, access to buprenorphine is greater than that of methadone, and its use in mainstream health settings may reduce the stigma associated with being treated in special "addiction clinics." In addition to providing an alternative to methadone, buprenorphine is used in some countries where methadone is not available (e.g., Lebanon, United Arab Emirates). In these countries, the introduction of buprenorphine represents a major step forward in promoting the development of addiction care within the health service system.

\section{Naltrexone}

In Russia, a country with a rapidly expanding HIV problem, neither methadone nor buprenorphine are currently available. As a result of a research partnership between Russian and US researchers, naltrexone, in both tablet and extended release forms, has been introduced into Russia via research efforts, and its use is expanding in Russian addiction treatment hospitals. ${ }^{31,32}$ While the extent of its use is limited, it represents an important first step in introducing and promoting the use of evidence-based treatments in Russia. ${ }^{33}$ 


\section{Screening and Assessment Tools}

A necessary step in addressing drug and alcohol problems in a society is being able to accurately identify patients with substance use problems, assess their severity, and collect adequate clinical data to develop a meaningful treatment plan. Research over the past several decades has led to the development of a number of validated screening and assessment instruments that can systematically and accurately provide information on the absence or presence, and severity, of a drug or alcohol problem. These include the ASSIST, ${ }^{34}$ AUDIT, ${ }^{35}$ CRAFFT, ${ }^{36}$ DAST, ${ }^{37,38}$ and the Addiction Severity Index. ${ }^{39}$ Many of these instruments have been adopted by physicians and clinicians in many low- and middle-income countries, where resources for addressing addiction problems are limited.

\section{The Alcohol, Smoking and Substance Involvement Screening Test (ASSIST)}

The Alcohol, Smoking and Substance Involvement Screening Test (ASSIST) is a structured interview that collects information on lifetime and past 90-day use of alcohol, smokable tobacco, and other categories of drugs. ${ }^{34}$ The screener collects information on the frequency and consequences of substance use and lifetime injection drug use. The information collected with the ASSIST is used to categorize severity of use as mild, moderate, or severe. The ASSIST, which has been validated in a number of studies, has established psychometric properties. The development of the ASSIST is the result of an international collaboration led by the WHO, and, currently, there is a WHO Coordinating Center in Australia that is responsible for the dissemination and further development of the ASSIST.*

In addition to its screening functions, the ASSIST also has a "brief intervention" to be used with individuals who score in the moderate range of substance use severity. This brief intervention, designed to be administered in 10-15 minutes, has been shown to produce a significant reduction in substance use that is sustained to 12 months after administration. Because the ASSIST is designed to be used in primary care settings, its use has contributed to the effort to better inform and equip mainstream healthcare clinicians to address substance use problems in all healthcare settings..$^{40-42}$ The ASSIST has been translated into the UN languages and has been incorporated into the UNODC Treatnet curriculum package and widely disseminated. ${ }^{17}$

* Drug and Alcohol Services South Australia, Government of South Australia SA Health. Available from URL: http://www.dassa.sa.gov.au/site/page.cfm?u=210. 


\section{Addiction Severity Index (ASI)}

The Addiction Severity Index (ASI) is the first instrument developed with rigorous psychometric testing to support a comprehensive assessment of an individual's substance use disorder. ${ }^{39}$ The rationale for the ASI is that the severity of a substance use disorder is not defined solely by the type and amount of drug or alcohol used, but also by the consequences of use on medical, psychiatric, family, employment, and legal domains. The ASI is administered by a trained interviewer, takes approximately 45 minutes to complete, and raw data is converted to weighted scores of severity for drug and alcohol use and the five domains listed above. ASI data can then be used to guide the development of treatment plans congruent with each individual patient's problem areas.

During the past 30 years, the ASI has been widely disseminated throughout the US, and in many parts of the country it is a required assessment instrument. It has been regularly updated and revised to address changing substance-use patterns and epidemiology. ${ }^{43}$ With each revision, the psychometric properties of the new version are established to ensure its sound scientific foundation. The ASI has also been revised so that questions are generalizable across cultures, and it has been integrated into the UN Treatnet curriculum package. It has also been translated into the UN languages and widely adopted throughout the world.

\section{Behavioral Approaches to Addiction Treatment}

Many of the early "talk therapies" for drug abuse and addiction were based on peer-support approaches or some form of modified confrontational therapeutic community approach. ${ }^{44}$ In the 1980s and 1990s, a variety of new behavioral therapies that were backed by scientific evidence supporting their efficacy and application began to emerge. ${ }^{44-48}$ Two of these widely disseminated approaches, motivational interviewing and the Matrix Model, have contributed to the development of addiction services internationally.

\section{Motivational Interviewing}

Motivational interviewing (MI) is a directive, client-centered counselling approach that helps individuals explore their ambivalence regarding substance use and initiate behavior change. ${ }^{49,50} \mathrm{MI}$ brought to the addiction treatment field an effective, compassionate, clinical approach that helps motivate patients to make decisions to take positive action. It was developed within a research context and was one of three approaches evaluated in the seminal Project Match research study funded by the U.S. National Institute on Alcohol Abuse and Alcoholism. 
MI is likely the most widely disseminated evidence-based behavioral strategy for treating addiction. The major dissemination effort for MI resulted from the establishment of the Motivational Interviewing Network of Trainers (MINT), an international organization that promotes the use of MI, research into MI, and the training of MI practitioners. This organization was established by a group of MI trainers who had been trained by the authors of MI, William Miller and Stephan Rollnick. More than 2,000 trainers, now representing at least 47 languages, have been through the MINT process. The Treatnet curriculum module on the use of MI has been one of the most widely used of the Treatnet training topics.

\section{Matrix Model}

Since the early 1990s, the production and use of methamphetamine and other amphetamine-type stimulants (ATS) have rapidly escalated in many parts of the world; ATS are currently estimated to be the second most widely used type of illicit drug after cannabis. ${ }^{51}$ Despite several decades of research to identify medications for the treatment of ATS dependence, to date, no medications have demonstrated efficacy. ${ }^{52}$ One multi-element behavioral treatment approach that combines MI, cognitive behavioral therapy, patient and family education, and 12-Step facilitation therapy into an integrated outpatient treatment experience is the Matrix Model. This approach has been manualized with funding from NIDA and evaluated in a multi-site clinical trial funded by SAMHSA. ${ }^{53, *}$

The Matrix Model has been extensively disseminated in the US. With the designation of the Matrix Model as an evidence-based practice via the SAMHSA National Registry of Evidence-based Programs and Practices (NREPP) program, the Matrix Model represents one of the few evidencebased practices for treating individuals with ATS dependence, and for this reason there has been interest in the approach in areas of the world with extensive ATS use. Matrix dissemination efforts internationally have led to over 6,000 individuals being trained in the Matrix Model. Matrix trainers have conducted training sessions in all 50 of the US States, in 21 countries, and they have trained staff from 2,500 treatment agencies. The Matrix manuals have been translated into Thai, Arabic, Farsi, Spanish, Portuguese, Vietnamese, Slovakian, Afrikaans, and Japanese.

\footnotetext{
* The Matrix manual and supportive materials are available at URL: www.ncadi.samhsa.gov.
} 


\section{CASE STUDIES}

The following international case studies provide examples of successful advancements in addiction treatment and public health service that were driven by the best scientific evidence, multiagency international collaborative efforts, and the influence of public health leaders and committed service providers with a vision for the future.

\section{Vietnam}

Vietnam is a country of 90 million people that has a significant prevalence of drug use and HIV. From the time of the war with the US in the 1970s, injected heroin has been a significant public health problem. In 1993, the government of Vietnam opened Compulsory Centers ( 06 centers), where drug users were re-educated, punished, and rehabilitated, since addicts were viewed as a "social evil." The 06 centers were part of a policy toward drug users in which drug users could be arrested and, without due process, be immediately transported to the 06 centers, where they were routinely held involuntarily for two years (or longer, for repeat offenders). While in the 06 centers, there was no identifiable drug treatment and the primary activity was long hours of tedious manual labor. Although not called "jails," the 06 centers were far more oriented to punishment and control than to medical or psychiatric treatment.

The first case of HIV infection was detected in Vietnam in 1990; by 1999, there were 17,046 diagnosed cases of HIV infection. By 2012, the estimated number of HIV-infected individuals was 206,887. Studies over this time period suggest that injection drug use (IDU) was the likely major route of HIV transmission in 85 to 90 percent of HIV-positive individuals. ${ }^{54}$ Following passage in 2006 of the Law on HIV/AIDS Prevention and Control (the "HIV law"), the Vietnamese government, led by the Deputy Prime Minister, Truong Vinh Trong, initiated a plan to change the focus of the response to the IDU/heroin problem in Vietnam. The Ministry of Health, with support from UNODC, WHO, Global Fund, USAID, Family Health International, and the U.S. President's Emergency Plan for AIDS Relief (PEPFAR), began plans to introduce methadone into Vietnam.

Methadone treatment programs were piloted in 2008 in Hai Phong and Ho Chi Minh City as a result of the 2006 HIV law. These pilot programs were operated under guidelines developed by Vietnamese leaders and with extensive consultation from international experts. The resulting guidelines were grounded in scientific evidence, and an extensive training program was implemented by local and international clinical experts to promote development of a methadone treatment system based on best practices. With the success of pilot programs, the government decided to scale-up 
methadone programs in other provinces. ${ }^{55}$ By July 2013, 14,000 patients were in methadone treatment in 62 clinics in 20 Vietnamese provinces. The Ministry of Health has projected that methadone treatment will be provided for about 80,000 drug users in 2015.

Studies on the results of the methadone implementation in Vietnam have demonstrated promising results. ${ }^{56}$ In a four-site cohort study of 965 heroin users who started treatment in $2009,88.3$ percent were retained in methadone treatment for 12 months. Heroin use, as measured by urinalyses was reduced from 100 percent positive at admission to 21 percent positive at 60 days in treatment, and over the subsequent ten months, rates varied from ten to 17 percent positive. Other study results indicated substantial reductions in injection drug use and crime, as well as improvements in mental health and quality of life.

If the Ministry of Health succeeds in its planned service development, Vietnam will have gone from two pilot project clinics in 2008, to treating over 80,000 patients with methadone in 2015. ${ }^{57}$ This extraordinary expansion of treatment capacity brings with it huge challenges in service funding and workforce development. In 2011, Hanoi Medical University, in collaboration with SAMHSA and the University of California, Los Angeles, established an Addiction Technology Transfer Center to lead efforts to train clinical staff for the clinics being developed. Compounding the challenges is the fact that the consumption of amphetamine-type stimulants (ATS) has rapidly increased in Vietnam-1.5 percent of drug users in Vietnam in 2001 used ATS, whereas 6.5 percent did in 2012. ${ }^{8}$ In order to address this emerging problem, training programs in MI and the Matrix Model have been initiated to address the needs of treatment-seeking ATS users. In less than a decade, Vietnam has mounted a major public health effort to address the problems of drug use and HIV, overcoming many obstacles that typically derail many public health initiatives. ${ }^{59}$ The policies, collaborations, and focus on evidence-based practices that guided this system development have been firmly grounded in addiction science. The challenge for the next decade in Vietnam will be to continue expansion of the services to provide treatment access for all individuals who need them, to maintain the quality of the services, and to better integrate addiction services with HIV services and the larger healthcare system.

\section{Lebanon}

At the start of the $21^{\text {st }}$ century, services for the treatment of substance use disorders in Lebanon were a collection of therapeutic communities and a limited set of treatment services from psychiatrists and psychiatric hospitals. 
Although these resources were helpful to patients and communities, there was no organized outpatient treatment and no use of addiction medications. In 2003, Skoun Lebanese Addictions Center was created to deliver high quality, evidence-based outpatient addiction services. Heroin addiction was Lebanon's primary drug problem that was not being effectively addressed by existing treatment services. Skoun initiated their treatment services using a combination of harm reduction strategies, together with cognitive behavioral therapy (CBT), MI, and psychiatric treatment. It was clear to Skoun staff from the beginning that to effectively engage and treat individuals addicted to opiates using a harm reduction philosophy, they would need addiction medications as part of their services. Therefore, an initial question was whether to introduce methadone or buprenophine into Lebanon, where, to date, no medication-assisted treatment had been available. As Skoun clinicians reviewed practices associated with methadone and buprenorphine in Europe and the US, they decided that the clinical data on the efficacy of buprenorphine, along with its flexibility in dosing and service delivery logistics, made it the preferable agonist medication to introduce into Lebanon. Because rates of HIV are low in Lebanon, there was no perceived public health urgency for addressing the IDU problem, as there was in Vietnam, China, and countries in Eastern Europe.

Because there are close historical and cultural ties between Lebanon and France, it was not uncommon for opiate-addicted individuals from Lebanon to go to France and receive buprenorphine and return to Lebanon to participate in counseling treatment services at Skoun. As this practice developed and some pharmacies in Beirut established relationships with French pharmacies, burprenophine became available, in a limited manner, to patients at Skoun. From 2005-2011, several hundred patients were treated with buprenorphine in Lebanon. During this period, discussions continued with government officials about the clinical effectiveness of buprenorphine and its value in improving the lives of addicted individuals. The Pompidou Group, UNODC, and the WHO Eastern Mediterranean Region Office (EMRO) played important roles in hosting meetings to promote discussions of buprenorphine in Lebanon and arranging trips for Ministry of Health officials to France and Iran to visit treatment centers using medications to treat opiate addiction. The persistent advocacy and encouragement by individuals at Skoun, along with other addiction and public health leaders in Lebanon and representatives of international organizations, resulted in official governmental approval for the importation and use of buprenorphine for the treatment of opiate addiction in February 2012.

During the first 12 months after the approval of buprenorphine in Lebanon, 690 patients have been treated with buprenorphine, with the 
majority being in Beirut. ${ }^{60}$ Skoun has expanded services from its original clinic in Eastern Beirut to a second clinic in South Beirut sponsored by the Drosos Foundation, a Swiss foundation. This clinic, which was projected to enroll 75 individuals on buprenorphine in its first year, was met with tremendous demand for services, enrolling double that number (150) in its first nine months of operation. In addition to the medical doctors at Skoun, 45 psychiatrists have been registered by the Ministry of Health to prescribe buprenorphine. The use of buprenorphine in Lebanon is currently limited by a restricted distribution system (all medication has to be dispensed from two government hospitals in Beirut) and all buprenorphine is available only through patient fees, which are several hundred US dollars per month. Currently, there are efforts to work with the government to promote treatment (including treatment with buprenorphine) in place of incarceration for drug offenders. The availability and effectiveness of bupenorphine has made it possible to convince judges to implement this practice.

Unlike the situation in Vietnam, where an internationally financed, large-scale multiagency partnership produced a major "roll out" of methadone treatment and other addiction services, the situation in Lebanon was on a smaller scale, but the accomplishment was equally impressive. The introduction of buprenorphine and other outpatient evidence-based services was the result of the persistence and commitment of Lebanese clinicians, the Pompidou Group, UNODC, National Aids Program, and the WHO EMRO, together with receptive Ministry of Health officials. The political situation over the past decade in Lebanon has made it challenging to bring the issue of addiction treatment onto the governmental agenda. However, the diligence of a small group of dedicated professionals, together with international organizations, has added an important addiction service in Lebanon and has provided a positive regional example of the feasibility and value of medication-assisted treatment for addiction.

\section{Abu Dhabi, United Arab Emirates (UAE)}

Abu Dhabi is one of the seven Emirates on the Persian Gulf that make up the United Arab Emirates, a country of great wealth as a result of its extensive petroleum production. The population of the UAE is approximately eight million. It is a country of rapid change and extensive infrastructure development in all areas, including health care. The National Rehabilitation Center (NRC) was established in 2002 under the direction of the late president of the UAE. It is the principal source of treatment and rehabilitation for Emiratis with substance use disorders. It is also the organization that coordinates all aspects of drug abuse epidemiology, prevention, and workforce development. As of 2008, the NRC consisted of an 18-bed residential 
treatment and rehabilitation center, a nine-bed halfway house, and some outpatient services. The NRC was the officially recognized addiction treatment facility in Abu Dhabi, even though there were also some detoxification services provided in the major mental hospital in Abu Dhabi and some private psychiatric services were available.

In early 2009, the newly appointed director of the NRC, Hamad Al Ghafri, MD, invited a six-person team representing the ISAM to visit the NRC to provide technical assistance and recommendations for service development. At the time of this site visit, the NRC had a census of nine patients, who were undergoing extended hospital-based residential care for nine to12 months, and three individuals living in the halfway house. At that point, the majority of the patients being treated in the NRC facility were individuals released from prison, and it was not altogether clear if the NRC was completely a clinical program or if it also served as an extension of the prison authority. The nature of treatment services at the time was somewhat unclear, and while there were some very well qualified and knowledgeable psychiatrists and clinical staff, there was minimal organization to the available clinical program and little indication of evidence-based practices being offered.

Over the next three years, the NRC instituted a major expansion of addiction services, with a commitment to developing a quality continuum of care based on evidence-based medicine. The NRC recruited a medical director from Cairo University, Egypt, who was the then president of ISAM, and two other Egyptian psychiatrists who had extensive expertise and specialized training in addiction. The NRC appointed a training director who, together with a training expert from Kings College in London, implemented a comprehensive program of staff training in evidence-based practices with quality clinical supervision. A team of Emirati clinicians received extensive training in the Matrix Model of outpatient treatment to address the substantial problem of ATS use and dependence, and the NRC arranged for the importation of Suboxone to treat opioid dependence. A research director, who had previously held a senior position at NIDA, was hired to develop a program of clinical and services research. In 2013, an electronic medical record (EMR) system was implemented and, at present, the entire clinical record keeping system at the NRC is incorporated into this EMR system.

The NRC has moved from the 18-bed residential facility in the City of Abu Dhabi to a much larger set of offices and villas in the suburbs. The residential capacity has been expanded to 124 beds for men and a separate facility for women. Outpatient services (medical services, psychiatric services, addiction medications, and behavioral treatments) are integrated 
with the residential programs into a connected continuum of care. The treatment capacity has increased fivefold, from 67 patients treated in 2009, to 338 in 2012. ${ }^{61}$ Plans are underway for the development of a satellite facility in a northern sector of the Emirates to make services more geographically accessible, and ground has been broken for a comprehensive treatment center that will provide an even greater treatment capacity. The service development at the NRC over the past five years has been extensive, and a foundational part of the service philosophy is the use of good science and treatments with a strong evidence base.

\section{SUMMARY}

The case studies presented are far from the only places where new sciencebased services have been developed in the past decade. Iran, China, and Malaysia have major programs of medication-assisted treatment development. South Africa and Iraq have large-scale training efforts with behavioral treatments. In all of these examples, addiction science and evidence-based treatments are core features of the service continuum. This application of medical and behavioral health research findings to addiction service system development is a welcome step toward the establishment of drug abuse and addiction treatment as a critical and legitimate public health service. A significant challenge for the future will be to find and mount the political will to redirect investments from incarceration/public safety interests to addiction treatment/public health interests. Further, to maximize the benefits of addiction services, it will be important to integrate these services into the broader health system to coordinate addiction care with treatment of other health conditions.

\section{Acronyms List:}

ASI $=$ The Addiction Severity Index

ASSIST $=$ The Alcohol, Smoking and Substance Involvement Screening Test

ATS = Amphetamine-type stimulants

$\mathrm{EMRO}=$ WHO Eastern Mediterranean Regional Office

IDU = Injection drug use

ISAM $=$ The International Society of Addiction Medicine

MI = Motivational interviewing

NIDA $=$ The U.S. National Institute on Drug Abuse

$\mathrm{NIH}=$ The U.S. National Institutes of Health

NRC $=$ The National Rehabilitation Center (UAE)

SAMHSA $=$ The U.S. Substance Abuse and Mental Health Services Administration $\mathrm{UNODC}=$ The United Nations Office on Drugs and Crime 
Conflicts of Interest: The authors have no conflicts of interest. Dr. Rawson is the Principal Investigator of the Cooperative Agreement for Workforce Development in Vietnam: HIV-Addiction Technology Transfer Center (2011-2014) and has served as a training consultant to SAMHSA on addiction treatment in Vietnam. Dr. Rawson was a member of the ISAM site visit team to the Abu Dhabi National Rehabilitation Center in 2009 and provided consultation to the NRC on outpatient services. Drs. Rawson and Rieckmann are Co-Principal Investigators on an evaluation of the Skoun Program in Beirut, under contract to the Drosos Foundation. Dr. Gust is Director, International Program at the U.S. National Institute on Drug Abuse, where he coordinates and manages Institute programs involving international research, training, and communication.

Acknowledgements: The authors would like to thank Le Minh Giang, MD, PhD, Hanoi Medical University, Nguyen, Nhu, MD, PhD, Family Health International, and Kevin Mulvey, PhD and Hoang Vu, MD, SAMHSA, Hanoi Vietnam; Nadya Mikdashi, PhD, and Ramzi Haddad, MD, Skoun Addiction Treatment Center, Beirut Lebanon; and Hamad Al Ghafri, MD, PhD, and Tarek Abdul Gawad, MD, Abu Dhabi, UAE. This chapter was supported by the SAMHSA agreement listed above to Dr. Rawson and the Drosos Foundation contract for the evaluation of the Skoun Chiyah Clinic to Drs. Rawson and Rieckmann. In addition, support was provided via D43TW009120, a UCLA-Cairo University Training Grant funded by the NIH Fogarty Center, Richard Rawson, PI.

\section{REFERENCES}

1. Rawson RA, Obert JL. The substance abuse treatment system in the US. What is it? What does it do? Myths and misconceptions. In: Zweben JE, Lambert S, (editors). Occupational Medicine: A State of the Art Review. Philadelphia (PA): Hanley and Belfus; 2002. p. 1-21.

2. United Nations International Drug Control Programme. The social impact of drug abuse. Copenhagen: World Summit for Social Development; 1995.

3. National Drug Intelligence Center. The economic impact of illicit drug use on American society. Washington (DC): United States Department of Justice; April 2011. Available from URL: http://www.justice.gov/archive/ndic/pubs 44/44731/44731p.pdf (Accessed 10 September 2013).

4. National Center on Addiction and Substance Abuse. Family matters: substance abuse and the American family: a CASA white paper. New York (NY): CASA at Columbia University; 2005.

5. Chandler RK, Fletcher BW, Volkow ND. Treating drug abuse and addiction in the criminal justice system: improving public health and safety. JAMA. 2009; 301:183-90.

6. Jensen E, Gerber J, Mosher C. Social consequences of the war on drugs: the legacy of failed policy. Crim Justice Policy Rev. 2004;15:100-21.

7. Schroedel JR, Fiber P. Punitive versus public health oriented responses to drug use by pregnant women. Yale J Health Policy Law Ethics. 2001;1:217-35. 
8. Dole VP, Nyswander M. A medical treatment for diacetylmorphine (heroin) addiction: a clinical trial with methadone hydrochloride. JAMA. 1965;193: 646-50.

9. National Institutes of Health. NIH grant will help translate addiction research into practice. Bethesda (MD): NIH; 2011. Available from URL: http://www. nih.gov/news/health/oct2011/niaaa-26.htm (Accessed 10 September 2013).

10. National Center on Addiction and Substance Abuse. Addiction medicine: closing the gap between science and practice. New York (NY): CASA at Columbia University; 2012.

11. Institute of Medicine. Bridging the gap between practice and research: forging partnerships with community-based drug and alcohol treatment. In: Lamb S, Greenlick MR, McCarty D (editors). Committee on Community-Based Drug Treatment. Washington (DC): National Academy Press;1998.

12. National Institute on Drug Abuse. Clinical Trials Network. Bethesda (MD): NIDA; 2013. Available from URL: http://www.drugabuse.gov/about-nida/ organization/cctn/ctn (Accessed 10 September 2013).

13. Addiction Technology Transfer Center. Who we are. 2013. Available from URL: http://www.attcnetwork.org/aboutus/index.asp (Accessed 10 September 2013).

14. Condon TP, Miner LL, Balmer CW, Pintello D. Blending addiction research and practice: strategies for technology transfer. J Subst Abuse Treat. 2008;35: 156-60.

15. Substance Abuse and Mental Health Services Administration. TIP Series: Treatment Improvement Protocols. Rockville (MD): SAMHSA. Available from URL: http://store.samhsa.gov/list/series?name=TIP-Series-TreatmentImprovement-Protocols-TIPS (Accessed 10 September 2013).

16. National Institute on Drug Abuse. Fellows World Map, Text-only Version. Bethesda (MD): NIDA; 2013. Available from URL: http://international.drug abuse.gov/fellowships/fellows-world-map-accessible (Accessed 10 September 2013).

17. Tomás-Rosselló J, Rawson RA, Zarza MJ, Bellows A, Busse A, et al. United Nations Office on Drugs and Crime international network of drug dependence treatment and rehabilitation resources centres: Treatnet. Subst Abuse. 2010; 31:251-63.

18. Saenz E, Busse A, Tomas-Rosello J, Clark N. Major international challenges in addiction treatment: the experience of Treatnet and beyond. In: El-Guebaly, N. Galanter, M. and Carra, G (editors). The Textbook of Addiction Treatment International Perspective. Springer. In press.

19. United Nations Office on Drugs and Crime. Drug dependence treatment: training package. Vienna: UNODC; 2007. Available from URL: http://www.unodc. org/ddt-training/treatment/general.htm (Accessed 10 September 2013).

20. Leshner AI. Addiction is a brain disease, and it matters. Science. 1997;278:45-7.

21. Volkow ND, Fowler JS, Wang GJ. The addicted human brain viewed in the light of imaging studies: brain circuits and treatment strategies. Neuropharmacology, 2004;47:3-13. 
22. Joseph H, Stancliff S, Langrod J. Methadone maintenance treatment (MMT): a review of historical and clinical issues. Mt Sinai J Med. 2000;67:347-64.

23. Centers for Disease Control. Methadone maintenance treatment. IDU/HIV Prevention; February 2002. Available from URL: http://www.cdc.gov/idu/ facts/MethadoneFin.pdf (Accessed 10 September 2013).

24. Corsi KF, Lehman WK, Booth RE. The effect of methadone maintenance on positive outcomes for opiate injection drug users. J Subst Abuse Treat. 2009; 37:120-6.

25. Langendam MW, van Brussel GH, Coutinho RA, van Ameijden EJ. Methadone maintenance and cessation of injecting drug use: results from the Amsterdam Cohort Study. Addiction. 2000;95:591-600.

26. U.S. Food and Drug Administration. Subutex and Suboxone approved to treat opiate dependence. Silver Spring (MD): FDA; 8 October 2002. Available from URL: http://www.fda.gov/Drugs/DrugSafety/PostmarketDrugSafety InformationforPatientsandProviders/ucm191521.htm (Accessed 10 September 2013).

27. Carrieri MP, Amass L, Lucas GM, Vlahov D, Wodak A, Woody GE. Buprenorphine use: the international experience. Clin Infect Dis. 2006;43: S197-215.

28. Mark TL, Kassed CA, Vandivort-Warren R, Levit KR, Kranzler HR. Alcohol and opioid dependence medications: prescription trends, overall and by physician specialty. Drug Alcohol Depend. 2009;99:345-9.

29. Arfken CL, Johanson CE, di Menza S, Schuster CR. Expanding treatment capacity for opioid dependence with office-based treatment with buprenorphine: national surveys of physicians. J Subst Abuse Treat. 2010;39: 96-104.

30. Mintzer IL, Eisenberg M, Terra M, MacVane C, Himmelstein DU, Woolhandler $\mathrm{S}$. Treating opioid addiction with buprenorphine-naloxone in communitybased primary care settings. Ann Family Med. 2007;5:146-50.

31. Krupitsky E, Nunes EV, Ling W, Illeperuma A, Gastfriend DR, Silverman BL. Injectable extended-release naltrexone for opioid dependence: a doubleblind, placebo-controlled, multicentre randomised trial. Lancet 2011;377: 1506-13

32. Krupitsky EM, Zvartau EE, Masalov DV, Tsoi MV, Burakov AM, et al. Naltrexone for heroin dependence treatment in St. Petersburg, Russia. J Subst Abuse Treat. 2004;26:285-94.

33. Krupitsky E, Zvartau E, Woody G. Use of naltrexone to treat opioid addiction in a country in which methadone and buprenorphine are not available. Curr Psychiatry Rep. 2010;12:448-53.

34. Humeniuk R, Ali R, Babor T, Souza-Formigoni ML, de Lacerda RB, et al. A randomized controlled trial of a brief intervention for illicit drugs linked to the Alcohol, Smoking, and Substance Involvement Screening Test (ASSIST) in clients recruited from primary healthcare settings in four countries. Addiction. 2012;107:957-66. 
35. Babor TF, Higgins-Biddle JC, Saunders JB, Monteiro MG. The Alcohol Use Disorders Identification Test: guidelines for use in primary care. 2nd edition. Geneva: World Health Organization; 2001.

36. Knight JR, Shrier LA, Bravender TD, Farrell M, Vander Bilt J, Shaffer HJ. A new brief screen for adolescent substance abuse. Arch Pediatr Adolesc Med. 1999;153:591-6.

37. Skinner HA. The Drug Abuse Screening Test. Addict Behav. 1982;7:363-71.

38. Yudko E, Lozhkina O, Fouts A. A comprehensive review of the psychometric properties of the Drug Abuse Screening Test. J Subst Abuse Treat. 2007;32: 189-98.

39. McLellan AT, Luborsky L, Woody GE, O’Brien CP. An improved diagnostic evaluation instrument for substance abuse patients. The Addiction Severity Index. J Nerv Ment Dis. 1980;168:26-33.

40. Saitz R, Alford DP, Bernstein J, Cheng DM, Samet J, Palfai T. Screening and brief intervention for unhealthy drug use in primary care settings: randomized clinical trials are needed. J Addict Med. 2010;4:123-30.

41. D'Onofrio G, Degutis LC. Preventive care in the emergency department: screening and brief intervention for alcohol problems in the emergency department: a systematic review. Acad Emerg Med. 2002;9:627-38.

42. Humeniuk R, Dennington V, Ali R. The effectiveness of a brief intervention for illicit drugs linked to the Alcohol, Smoking and Substance Involvement Screening Test (ASSIST) in primary health care settings: a technical report of phase III findings of the WHO ASSIST randomized controlled trial. Geneva: World Health Organization; 2008.

43. McLellan AT, Cacciola JS, Alterman AI. The ASI as a still developing instrument: response to Mäkelä. Addiction. 2004;99:411-2.

44. Brunette M, Mueser K, Drake R. A review of research on residential programs for people with severe mental illness and co-occurring substance use disorders. Drug Alcohol Rev. 2004;23:471-81.

45. Marlatt GA, Donovan DDM, (editors). Relapse prevention: maintenance strategies in the treatment of addictive behaviors. New York (NY): Guilford Press; 2005.

46. Carroll KM, Onken LS. Behavioral therapies for drug abuse. Am J Psychiatry. 2005;162:1452.

47. Higgins ST, Delaney DD, Budney AJ, Bickel WK, Hughes JR, et al. A behavioral approach to achieving initial cocaine abstinence. Am J Psychiatry. 1991;148:1218-24.

48. Prendergast M, Podus D, Finney J, Greenwell L, Roll J. Contingency management for treatment of substance use disorders: a meta-analysis. Addiction. 2006;101:1546-60.

49. Miller WR, Rollnick S. Motivational interviewing: preparing people to change addictive behavior. New York (NY): Guilford press; 1991.

50. Miller WR, Rollnick S. Motivational interviewing: preparing people for change. New York (NY): Guilford press; 2002. 
51. United Nations Office on Drugs and Crime. World Drug Report 2013. Vienna: UNODC; 2013. Available from URL: http://www.unodc.org/wdr/ (Accessed 10 September 2013).

52. Rawson R, Ling W, Mooney L. Clinical management: methamphetamine. In: Galanter M, Kleber HD, (editors). Textbook of Substance Abuse Treatment. Arlington (VA): American Psychiatric Publishing; 2014.

53. Rawson R, Marinelli-Casey P, Anglin MD, Dickow A, Frazier Y, et al. A multisite comparison of psychosocial approaches for the treatment of methamphetamine dependence. Addiction. 2004;99:708-17.

54. Vietnam Ministry of Health. Report on HIV/AIDS situation and prevention and control HIV/AIDS in 2011. Direction and major tasks in 2012. 2012;73. [In Vietnamese]

55. Vuong T, Ali R, Baldwin S, Mills S. Drug policy in Vietnam: A decade of change? Int J Drug Policy. 2012;23:319-26.

56. Vietnam Ministry of Health, Hai Phong Provincial AIDS Center, Ho Chi Minh City Provincial AIDS Committee, FHI 360, U.S. Agency for International Development. Effectiveness evaluation of the pilot program for treatment of opioid dependence with methadone in Hai Phong and Ho Chi Minh Cities: Component II - Impact on physical health, mental health, society and quality of life; 2011.

57. Nguyen TTM, Nguyen LT, Pham MD, Vu, H, Mulvey KP. Methadone maintenance therapy in Vietnam: an overview and scaling-up plan. Adv Prev Med. 2012;2012:732484.

58. United Nations Office on Drugs and Crime. Amphetamine-type stimulants in Viet Nam - Review of the availability, use and implications for health and security. Vienna: UNODC; 2012.

59. Hemenway D. Why don't we spend enough on public health? N Eng J Med. 2010;362:1557-8.

60. Rawson RA, Rieckmann T. Report on Skoun Chiyah Clinic. Zurich: Drosos Foundation; 2013.

61. Al Ghafri H. The National Rehabilitation Center of Abu Dhabi. Annual Meeting of the Saudi Arabia Psychiatric Association. Riyadh, Saudi Arabia; 2013. 